\title{
MENINGKATKAN PENGETAHUAN KEPADA ANAK MELALUI PENGAJARAN DAN PEMBELAJARAN
}

\author{
Hannisa Rahmaniar ${ }^{1}$, Denanto Dwi Nugroho, Intan Deliar ${ }^{2}$ \\ hannisa@uika-bogor.ac.id \\ Dosen Fakultas Ekonomi ${ }^{1}$, Mahasiswa KKN Kelompok 44 Tahun $2018^{2}$
}

\begin{abstract}
ABSTRAK
Pengajaran dan pembelajaran yang baik harus disampaikan dengan baik pula agar mendapat banyak pengetahuan. Dimulai dari pengajaran, pembelajaran, metode, media yang digunakan, dan fasilitas yang digunakan. KKN kelompok 44 UIKA ini bertujuan untuk meningkatkan pengetahuan anak-anak mengenai informasi yang kami berikan. Pengetahuan merupakan hasil pengindraan manusia atau hasil tahu seseorang terhadap objek melalui indra yang dimilikinya seperti mata, hidung, telinga, dan sebagainya. Program yang kami jalankan berupa pengajaran di MI Nur Sidqul Wahid, pengajaran di Paud Al-Ikhsan, pengajaran di Paud Anggrek, dan Bimbel. Pada bidang keagamaan, KKN 44 UIKA melakukan kegiatan rutin yang hampir setiap hari yaitu mengajar TPA, mengikuti pengajian Ibu-ibu, pengajian Bapak-bapak, dan juga pengajian remaja. Pada bidang kesehatan, KKN 44 UIKA melakukan kegiatan yaitu penyuluhan perilaku hidup bersih dan sehat, senam sehat, cek kesehatan gratis, dan membantu kegiatan Posyandu. Pada bidang ekonomi, KKN 44 UIKA melakukan kegiatan yaitu penyuluhan menabung sejak dini. Pada bidang teknik, KKN 44 UIKA melakukan kegiatan yaitu pembelajaran dasar komputer dan pembuatan gapura. Adapun metode yang kami gunakan yaitu metode bimbingan dan penyuluhan, metode belajar melalui bermain, metode belajar talking stick, metode belajar dengan media.
\end{abstract}

Kata Kunci: Metode Belajar, Pengajaran, Pembelajaran.

\section{PENDAHULUAN}

Kuliah Kerja Nyata (KKN) merupakan salah satu kegiatan pengabdian mahasiswa kepada masyarakat. Pengabdian kepada masyarakat ini seringkali ditujukan pada desa-desa yang berada di berbagai kabupaten di Indonesia. Universitas Ibn Khaldun Bogor adalah salah satu perguruan tinggi yang mewajibkan setiap mahasiswanya mengabdi kepada masyarakat dengan mengikuti program KKN Tematik Terintegrasi.
KKN Tematik Terintegrasi 2018 ini, Universitas Ibn Khaldun Bogor diselenggarakan pada Kabupaten Bogor di wilayah bagian Barat. Adapun salah satu kelompok yang mengikuti program tersebut adalah kelompok KKN 44. Kelompok KKN 44 ini mendapat tugas mengabdi pada masyarakat di Kecamatan Pamijahan, tepatnya di Desa Gunung Bunder 1.

Desa Gunung Bunder 1 memiliki 8 RW, masing-masing Rw memiliki ciri khas yang berbeda-beda. Namun pada kesempatan kali ini, kami ditempatkan di 
RW 01 yaitu di Kampung Wates. Kampung Wates memiliki jumlah penduduk yang lebih banyak dibandingkan dengan kampung lainnya yang berada di Desa Gunung Bunder 1, oleh sebab itu Kampung Wates memiliki 5 RT. Sebagian penduduk berprofesi sebagai petani dan peternak.

Sarana dan prasarana yang ada di RT 03/RW 01 cukup baik, terdapat 1 POSYANDU yang berada di RT 03, memiliki beberapa tempat ibadah, 1 Madrasah Ibtidaiyyah dan beberapa Taman Kanak-kanak. Dalam menjalankan tugasnya untuk membantu masyarakat, KKN 44 UIKA memiliki program kerja dibidang pendidikan, bidang keagamaan, bidang kesehatan, bidang ekonomi, bidang teknik.

Pada bidang pendidikan, KKN 44 UIKA melakukan kegiatan rutin yang hampir setiap hari yaitu pengajaran di MI Nur Sidqul Wahid, pengajaran di Paud AlIkhsan, pengajaran di Paud Anggrek, dan Bimbel. Pada bidang keagamaan, KKN 44 UIKA melakukan kegiatan rutin yang hampir setiap hari yaitu mengajar TPA, mengikuti pengajian Ibu-ibu, pengajian Bapak-bapak, dan juga pengajian remaja. Pada bidang kesehatan, KKN 44 UIKA melakukan kegiatan yaitu penyuluhan perilaku hidup bersih dan sehat, senam sehat, cek kesehatan gratis, dan membantu kegiatan Posyandu. Pada bidang ekonomi, KKN 44 UIKA melakukan kegiatan yaitu penyuluhan menabung sejak dini. Pada

\section{Kondisi Wilayah}

Desa Gunung Bunder 1 secara struktural merupakan bagian integral yang tak terpisahkan dari sistem perwilayahan Kecamatan Pamijahan Kabupaten Bogor. Desa Gunung Bunder 1 adalah salah satu Desa dari 15 desa yang ada di Kecamatan bidang teknik, KKN 44 UIKA melakukan kegiatan yaitu pembelajaran dasar komputer dan pembuatan gapura. Selain program dari ke 5 bidang tersebut, kami pun memiliki 2 program umum yaitu lomba 17 Agustus yang dikhususkan untuk masyarakat yang diselenggarakan di MI Nur Sidqul Wahid dan juga program penanaman bibit pohon.

Sebagian besar program yang KKN 44 UIKA jalankan, difokuskan untuk anakanak. Maka dari itu tema yang kami ambil untuk pedoman program kerja yang dilaksanakan selama KKN berlangsung yaitu

"MENINGKATKAN PENGETAHUAN KEPADA ANAK MELALUI PENGAJARAN DAN PEMBELAJARAN". Alasan kami mengambil tema tersebut, karena sebagian besar dari program kerja kami adalah mengajar dengan menggunakan beberapa metode dan media yang tidak membosankan untuk anak-anak. Materi yang kami ajarkan berupa pelajaran yang diajarkan di sekolah, materi tentang perilaku hidup bersih dan sehat, ilmu dasar komputer, bahasa, akhlak yang baik, dan lain sebagainya.

Tujuan akhir dari kegiatan ini adalah menciptakan suasana belajar yang menyenangkan sehingga anak tidak bosan dalam mengikuti pelajaran, mempermudah anak untuk memahami dan menerapkan materi yang diberikan serta merubah pengetahuan anak dan masyarakat tentang informasi yang telah kami beri.

Pamijahan yaitu Desa Cibunian, Purwabakti, Ciasmara, Gunung sari, Gunung Bunder 2, Gunung Bunder 1, Cibening, Gunung Picung, Cibitung Kulon, Cibitung Wetan, Pamijahan, pasaeran, Gunung Menyan, Cimayang, dan Desa Ciasihan 
a. Tipologi Desa/Kelurahan:

Perladangan

b. Klasifikasi Desa/Kelurahan: Swadaya

c. Kategori Desa/Kelurahan: Madya

d. Luas Wilayah : 330, $36 \mathrm{Ha}$

e. Batas Wilayah

Sebelah Utara : Desa Cibening

Sebelah Selatan :Desa Gunung Bunder 2

Sebelah Barat :Desa Gunung picung

Sebelah Timur : Desa Tapos 1 dan 2

Jumlah Penduduk : 8638 jiwa

g. Jumlah Kepala Keluarga: 2194 KK

h. Jumlah Penduduk : 8638 jiwa

\begin{tabular}{|l|l|c|}
\hline No & Jenis Kelamin & $\begin{array}{c}\text { Jumlah } \\
\text { (Jiwa) }\end{array}$ \\
\hline 1 & Laki-laki & 4522 \\
\hline 2 & Perempuan & 4116 \\
\hline \multicolumn{2}{|c|}{ Jumlah Penduduk } & 8638 \\
\hline
\end{tabular}

i. Pekerjaan/Mata Pencaharian

Petani

Buruh Tani/Nelayan

: 220 Orang

Buruh Pabrik

: 807 Orang

PNS

Pegawai Swasta

: 427 Orang

: 11 Orang

Wiraswasta/Pedagang

: 210 Orang

:730 Orang

Lainnya, sebutkan JASA

: 284 Orang

\section{j. Sarana dan Prasarana}

Kantor Desa : : 1 Buah

Prasarana Kesehatan

Posyandu : :9 Buah

Bidan :1 Buah

Dukun Bayi Terlatih : 7 Buah

Prasarana Pendidikan :

$\begin{array}{ll}\text { PAUD/TK/RA } & : 7 \text { Buah } \\ \text { SD/MI } & : 22 \text { Buah } \\ \text { SLTP/MTs } & : 3 \text { Buah } \\ \text { SLTA/SMK } & : 1 \text { Buah } \\ \text { Prasarana Ibadah } & : \\ \text { Masjid } & : 17 \text { Buah } \\ \text { Mushola } & : 22 \text { Buah } \\ \text { Majlis Ta'lim } & : 33 \text { Buah } \\ \text { Pondok Pesantren } & : 13 \text { Buah }\end{array}$

Prasarana Umum

Lapangan Tenis Meja : 1 Buah

Desa Gunung Bunder 1 memiliki 8 RW, namun pada $\mathrm{KKN}$ ini kami diberi kesempatan oleh Kepala Desa untuk bertugas di Kampung Wates tepatnya di RW 01 RT 03. Kondisi masyarakat di Kampung Wates RT 03/ RW 01 dalam bidang pendidikan masih tergolong rendah dikarenakan sarana pendidikan tingkat SMP dan tingkat SMA sangat jauh untuk dijangkau, sehingga lebih banyak warga hanya sebatas lulus SD/MI dan SMP saja. Kondisi perekonomian yang kebanyakan menengah kebawah adalah salah satu alasan masyarakat enggan untuk meneruskan pendidikan yang lebih tinggi. Mata pencaharian masyarakat kampung Wates rata-rata adalah petani dan peternak. Namun tak jarang remaja di kampung wates bekerja sebagai buruh di perantauan, sehingga kegiatan remaja di kampung wates sangat jarang.

Hampir seluruh masyarakat Kampung Wates beragama Islam. Saat kami menjalankan KKN di Kampung Wates, terdapat satu majlis ta'lim yang setiap hari digunakan untuk mengaji, baik pengajian ibu-ibu yang dilaksanakan setiap hari selasa pagi, pengajian bapak-bapak yang dilaksanakan setiap hari Minggu malam, pengajian remaja dilaksanakan pada hari Rabu malam dan Taman Pendidikan Anak (TPA) yang dilaksanakan setiap hari Senin-Sabtu. Namun, adapun permasalahan yang sering kali ditemukan pada anak-anak Kampung Wates yaitu kurangnya tata krama atau sopan santun terhadap teman ataupun kepada orang yang lebih tua darinya.

Pada kampung wates terdapat sumber mata air yang masih terjaga, aliran air yang sangat besar dan jernih adalah 
salah satu faktor warga menggunakan aliran air tersebut untuk aktivias sehari-hari mereka seperti mencuci, mandi, buang air, dan mebuang limbah kolam ikan. Dapat kami simpulkan bahwa perilaku hidup bersih dan sehat masyarakat kampung wates masih rendah. Selain itu kondisi kesehatan gigi pada anak-anak masih buruk karena masih banyak anak-anak yang mengalami karies gigi.

Pengetahuan anak-anak mengenai teknologi masih tergolong rendah, karena tidak ada fasilitas yang mendukung untuk belajar teknologi khususnya komputer. Sehingga ketika kami survei dan mewawancarai kepada anak-anak di kampung wates tentang fungsi dan cara pemakaian laptop mereka masih belum paham. Ketika kami mengajarkan tentang dasar komputer mereka sangat antusias untuk mempelajari laptop lebih dalam lagi.

Ketika kami datang untuk menjalankan KKN masyarakat kampung wates sangat antusias menyambut kami dan membantu dalam melaksanakan program kerja yang telah kami rancang sebelumnya.

\section{METODE PENGABDIAN}

Dalam program KKN tematik terintegrasi 2018 ini KKN kelompok 44 UIKA ini bertujuan untuk meningkatkan pengetahuan anak-anak mengenai informasi yang kami berikan. Pengetahuan merupakan hasil pengindraan manusia atau hasil tahu seseorang terhadap objek melalui indra yang dimilikinya seperti mata, hidung, telinga, dan sebagainya (Notoatmodjo, Soekidjo 2011). Dalam pengetahuan terdapat beberapa tingkatan yaitu (Notoatmodjo, Soekidjo 2014) : a. Tahu : memanggil memori yang telah ada sebelumnya setelah mengamati sesuatu.

b. Memahami : menginterpretasikan secara benar tentang objek yang diketahui.

c. Aplikasi : seseorang menggunakan prinsip yang diketahui tersebut pada situasi lain.

d. Analisis : kemampuan menjabarkan dan memisahkan kemudian mencari hubungan antar komponen yang terdapat dalam objek yang diketahui.

e. Sintetis : kemampuan untuk merangkum dalam satu hubungan yang logis dari komponen pengetahuan yang dimiliki.

f. Evaluasi : kemampuan melakukan penilaian terhadap objek tertentu.

Untuk dapat meningkatkan pengetahuan tersebut maka kami menggunakan metode pengabdian sebagai berikut :

1) Metode bimbingan dan penyuluhan

Pada metode ini guru/penyuluh memberikan beberapa materi atau informasi yang disampaikan kepada murid melalui lisan dan dengan menggunakan media berupa lagu dan video edukasi. Pada metode ini guru menjalin komunikasi 2 arah, agar terjalin kedekatan antara guru dan murid, sehingga murid tidak bosan saat menerima informasi yang diberikan. Metode ini digunakan untuk program kerja bimbingan belajar (bimbel), penyuluhan tentang kesehatan dan penyuluhan tentang pentingnya menabung sejak dini (Notoatmodjo, Soekidjo 2004)

2) Metode belajar melalui bermain Belajar yang paling efektif untuk PAUD adalah melalui bermain kreatif dan 
menyenangkan dan menyenangkan (Holis, Ade ). Dalam metode ini kami gunakan saat kami mengajar PAUD Al Ikhsan dan Pos PAUD Anggrek

3) Metode belajar talking stick

Talking stick adalah metode pembelajaran yang dilakukan dengan bantuan tongkat, siapa yang memegang tongkat wajib menjawab pertanyaan dari guru setelah siswa mempelajari materi pokok. Selain untuk melatih berbicara, model ini juga menuntut siswa dapat bekerjasama dengan temantemannya agar dapat mengerti dan siap untuk menjawab pertanyaan dari guru (Andreyaani, Yeyen dalam Suriani Siregar 2015). Metode in kami gunakan untuk membantu anak -anak dalam menghafal Surat-surat pendek AlQur'an dan do'a-do'a harian.

4) Metode belajar dengan media

Media yang digunakan adalah media audio visual,melalui media tersebut pembelajaran dapat lebih interaktif dan lebih memungkinkan terjadinya two way traffic dalam proses pembelajaran (Haryoko, Sapto 2009).

\section{REALISASI PROGRAM}

1. Program Kelompok
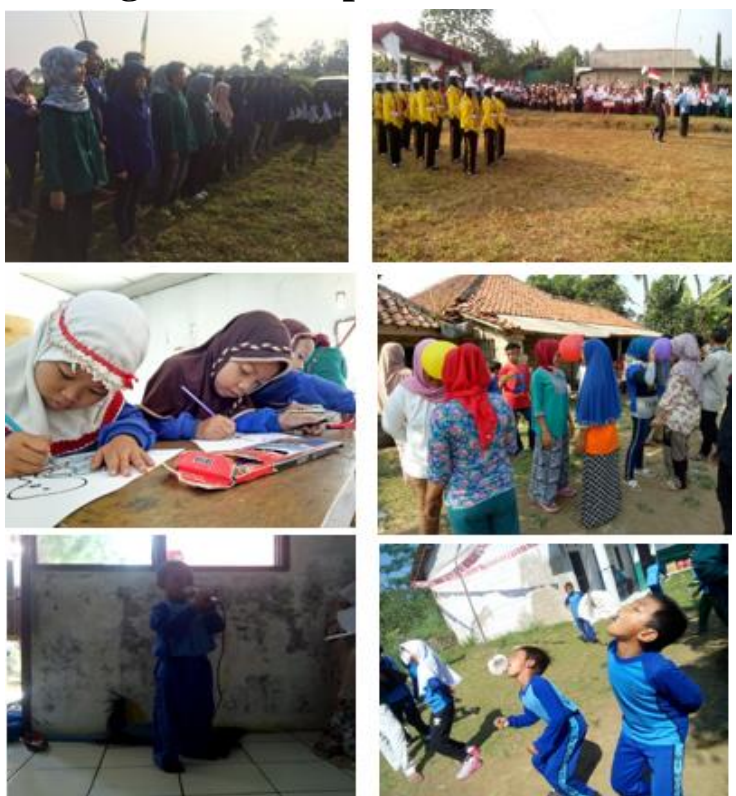

\section{Peringatan HUT RI}

Bentuk apresiasi kelompok KKN 44 dengan warga Kampung Wates dalam memeriahkan Hari Kemerdekaan RI yang ke 73 maka kami mengadakan kegiatan sebagai berikut :

a) Upacara Pengibaran Bendera

Upacara pengibaran bendera Merah Putih ini dilaksanakan di lapangan Kebun Jeruk Desa Gunung Bunder 1 pada pagi hari pukul 08.00 WIB, yang diikuti oleh seluruh elemen masyarakat Desa Gunung Bunder 1

b) Perlombaan 17 Agustus

Perlombaan ini dilaksanakan selama dua hari, yaitu pada tanggal 18 Agustus 2018 untuk perlombaan anak-anak dan pada tanggal 19 Agustus 2018 untuk perlombaan remaja dan orang tua. Kegiatan ini dilaksanakan di MI Nur Shidqul Wahid. 

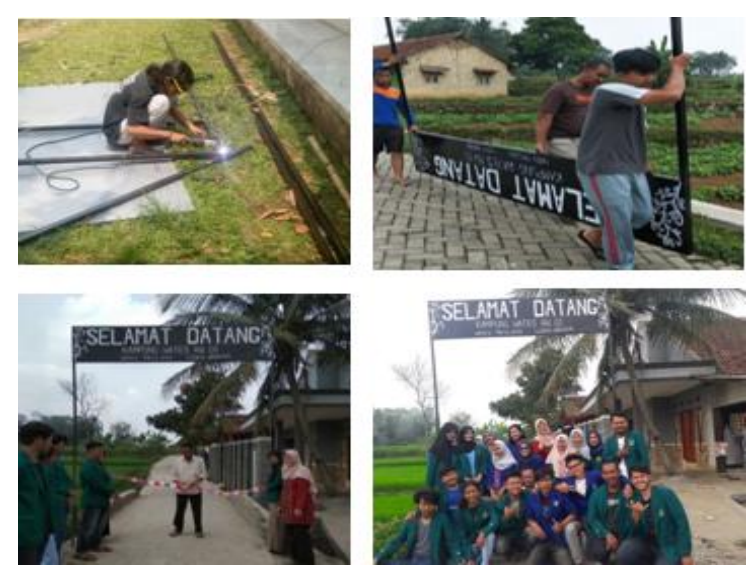

Pembuatan Gapura

Pembuatan Gapura bertujuan sebagai kenang-kenangan untuk Kp. Wates, dan juga sebagai petunjuk arah Kp. Wates RW 01. Gapura tersebut berbahann dasar besi dan cat berwarna hitam dan putih. Dan pembuatan Gapura ini bekerja sama dengan Universitas Trilogi Jakarta.
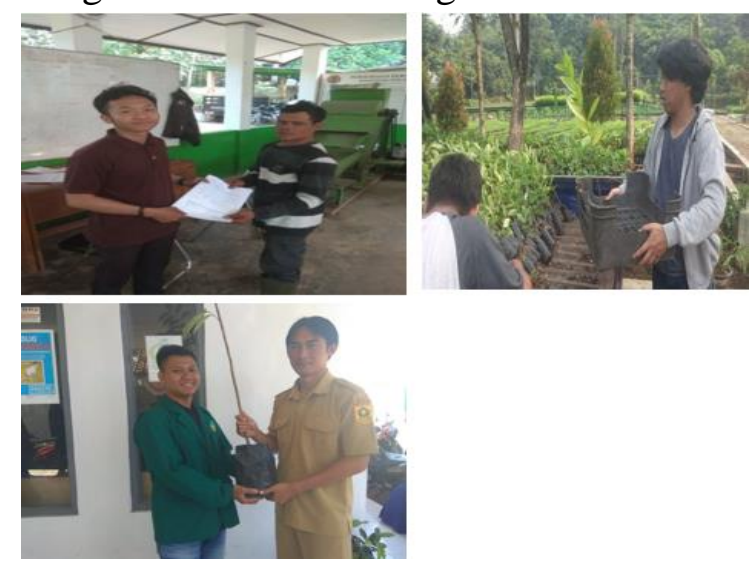

\section{Penanaman Bibit 1000 Pohon}

Penanaman 1000 Pohon bekerja sama dengan Institut Pertanian Bogor. Jenis Pohon yang kami ambil diantaranya adalah : pohon rambutan, pohon mangga, pohon durian, pohon sirsak, pohon salam, pohon mahoni, pohon petay, dan lain-lain. Penanaman 1000 Pohon ini bertujuan sebagai kenang-kenangan dari kelompok KKN 44, dan hasil dari pohon tersebut bisa membantu perekonomian masyarakat. Penyerahan bibit 1000 pohon ini diberikan kepada kepala Desa sebagai simbolis, ketua RW dan warga sekitar Kampung Wates.
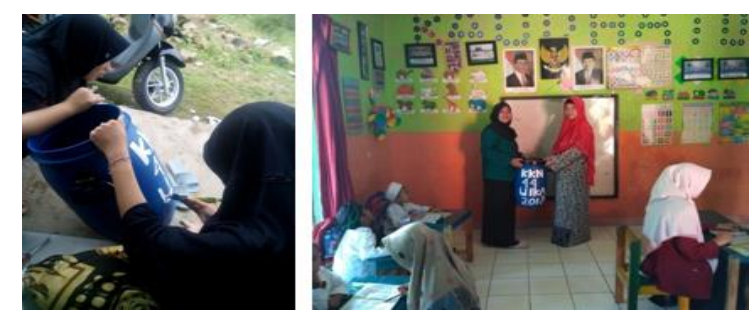

\section{Pengadaan Tong Sampah}

Kegiatan ini dilaksanakan sebagai kenangkenangan kelompok KKN 44 untuk MI dan PAUD yang ada di Kampung Wates. Hal ini kami ambil karena kurangnya kesadaran murid untuk membuang sampah pada tempatnya dikarenakan fasilitas pembuangan sampah yang kurang.

\section{Program PerBidang}

\section{Bidang Pendidikan}
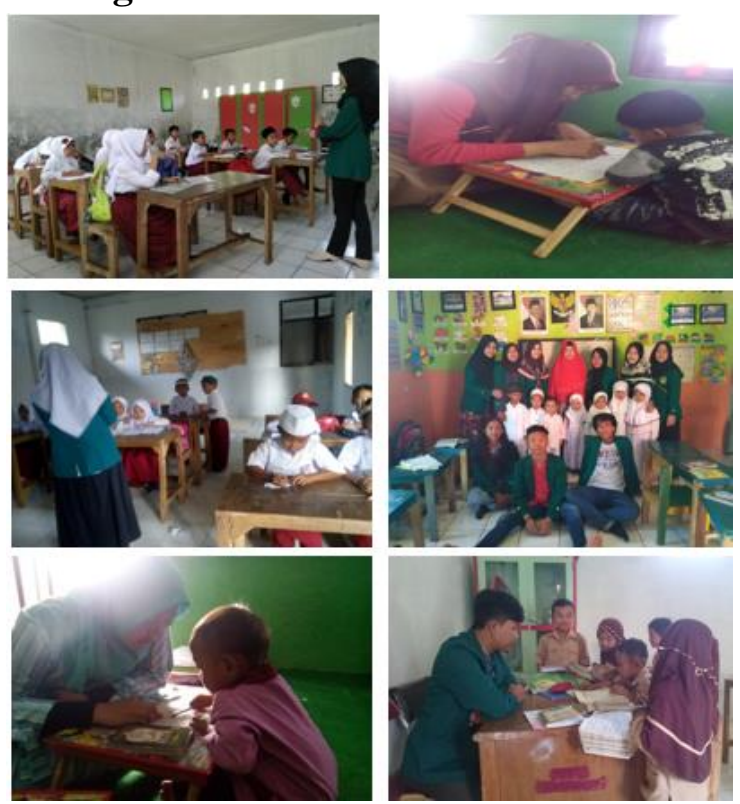

a) Mengajar MI dan PAUD

Salah satu kegiatan pada bidang pendidikan kami melakukan kegiatan belajarmengajar di MI Nur Shidqul Wajid, PAUD Al Ikhsan dan Pos PAUD Anggrek 1. Kami melakukan kegiatan mengajar pada hari Senin-Rabu 

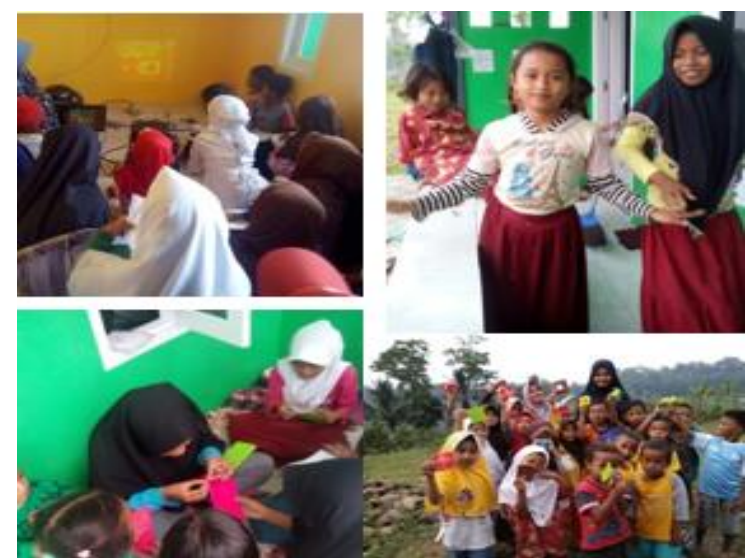

b) Bimbingan Belajar (Bimbel)

Bimbel diadakan di posko KKN 44, peserta yang mengikuti bimbel adalah anak-anak MI dan MTS yang tinggal tidak jauh dari posko KKN 44. Materi yang diajarkan mengenai Bahasa Inggris, Bahasa Arab dan prakarya.

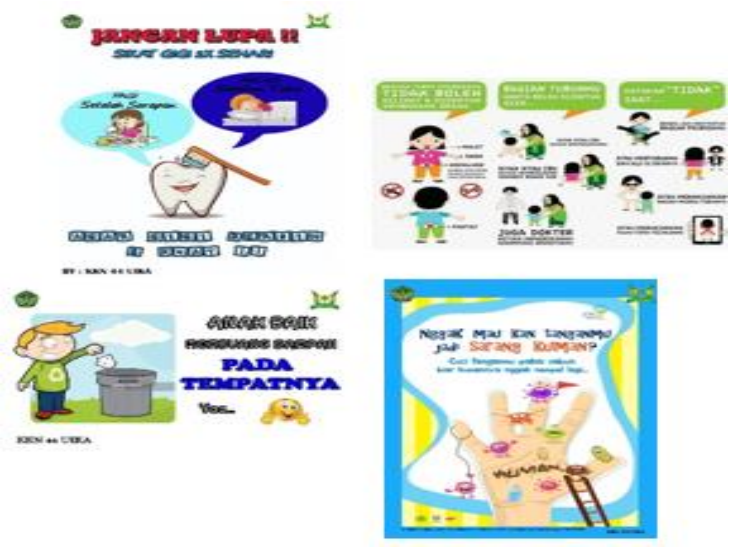

c) Membuat Media Pembelajaran

Tujuan dari pembuatan media pembelajaran ini adalah menciptakan suasana belajar yang menyenangkan sehingga anak tidak bosan dalam mengikuti pelajaran, mempermudah anak untuk memahami dan menerapkan materi yang diberikan serta merubah pengetahuan anak dan masyarakat tentang informasi yang telah kami beri. Foto media yang poster dan ss aplikasi dan video

\section{Bidang Ekonomi}

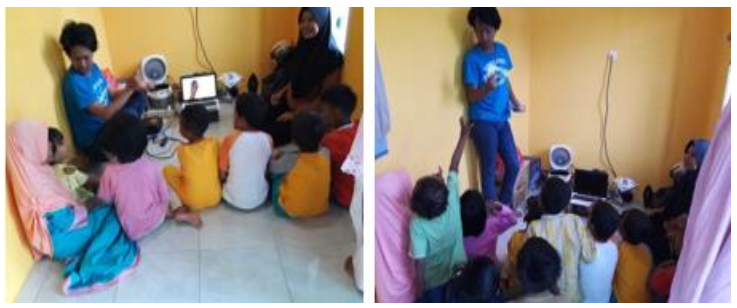

a) Penyuluhan Menabung

Program penyuluhan menabung sejak dini yang di laksanakan di Masyarakat sekitar posko tingkat anak-anak diKampung Wates. Kegiatan ini dilaksanakan menggunakan media Video Scribe agar informasi yang diberikan dapat diserap oleh anak-anak dengan materi tentang pentingnya menabung sejak dini, pengenalan jenis uang, dan cara menyisihkan uang jajan.

\section{Bidang Agama}
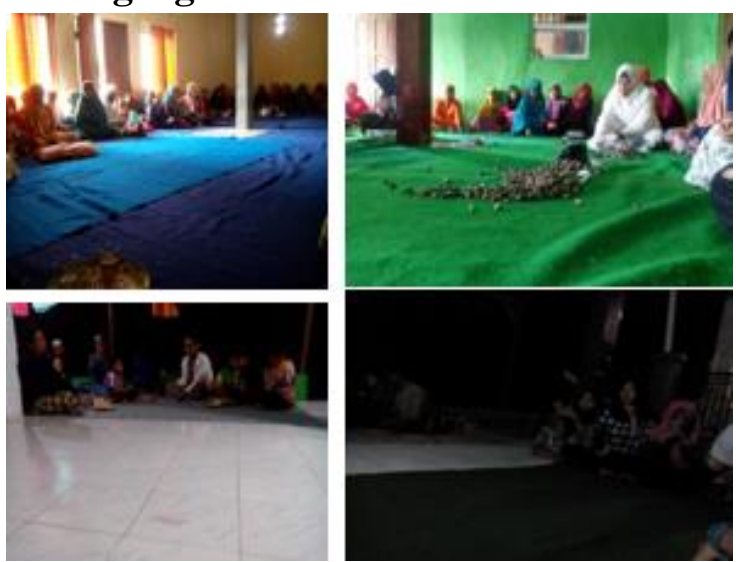

a) Pengajian

Pengajian ibu-ibu dilaksanakan setiap hari selasa pagi, pengajian bapak-bapak dilaksanakan setiap minggu malam dan pengajian remaja dilaksanakan pada rabu malam. Kegiatan dalam pengajian tersebut selain pembacaan Tahlil diisi juga dengan tausiah dari tokoh agama setempat. Dalam pengajian tersebut kami hanya mengikuti kegiatan yang telah ada 

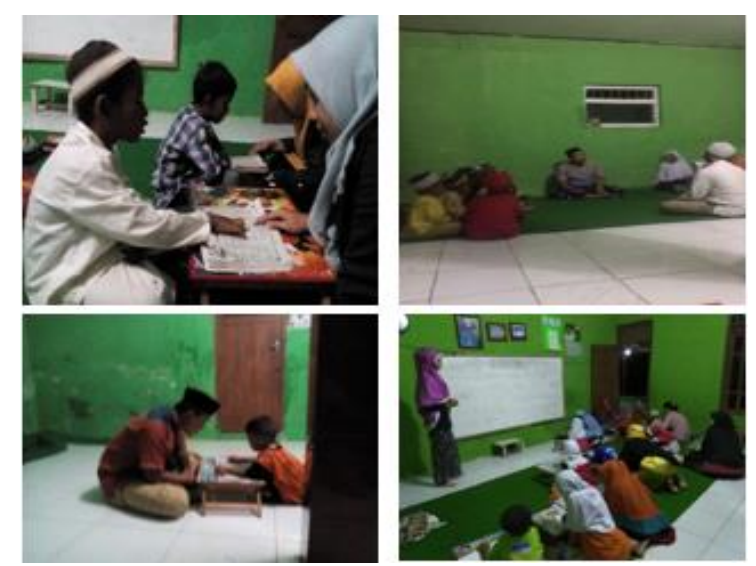

b) Taman Pendidikan Anak (TPA)

TPA ini diadakan setiap hari SeninSabtu pada pukul 18.30 WIB di Majlis Ta'lim yang berada di RT 03/ RW 01, kegiatan dalam TPA ini selain mengaji Iqra dan Al-Qur'an juga menghafal dan menulis surat-surat pendek. Untuk menguji anak-anak dalam menghafal surat-surat pendek dan do'a-do'a harian kami sering menggunakan kuis atau permainan agar anak-anak semangat dalam menghafal surat-surat pendek dan do'a-do'a harian.

\section{Bidang Kesehatan}

a) Penyuluhan Kesehatan

Dalam penyuluhan kesehatan ini kami memberikan informasi tentang :
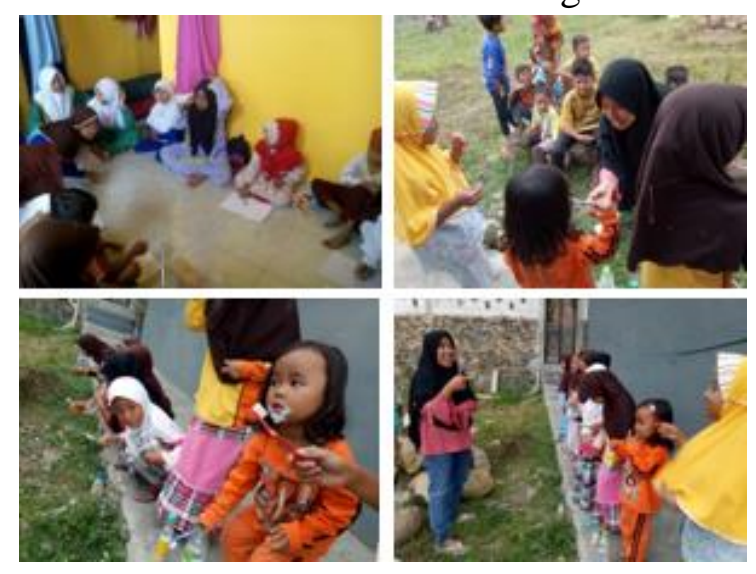

1. Sikat gigi yang baik dan benar

Sasaran penyuluhan sikat gigi ini adalah anak-anak yang tinggal tidak jauh dari posko KKN 44, metode yang digunakan untuk menyampaikan informasi tersebut adalah video, lagu dan poster. Selain memberikan informasi mengenai sikat gigi yang baik dan benar kami juga mengadakan praktik sikat gigi dengan baik dan benar.
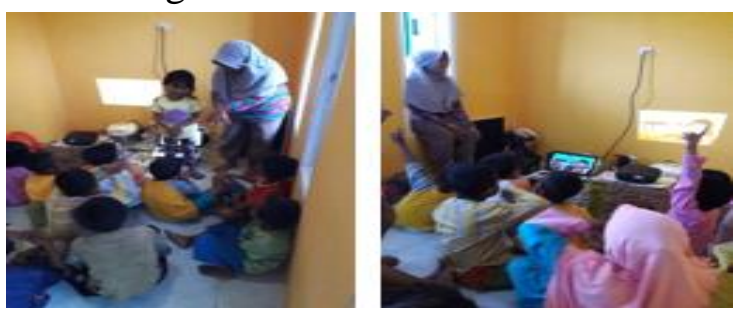

2. Cuci tangan pakai sabun

Penyuluhan cuci tangan pakai sabun ditujukan kepada anak-anak Kampung Wates, kebanyakan anakanak kampung wates kurang memperhatikan perilaku hidup bersih dan sehat seperti tangan yang kotor dan langsung memegang makanan tanpa mencuci tangan terlebih dahulu. Hak tersebut dapat menyebabkan penyakit seperti diare, Typus dan sebagainya. Penyuluhan cuci tangan pakai sabun ini menggunakan media video yaitu film pendek mengenai pentingnya mencuci tangan pakai sabun dan 6 langkah mencuci tangan yang benar.
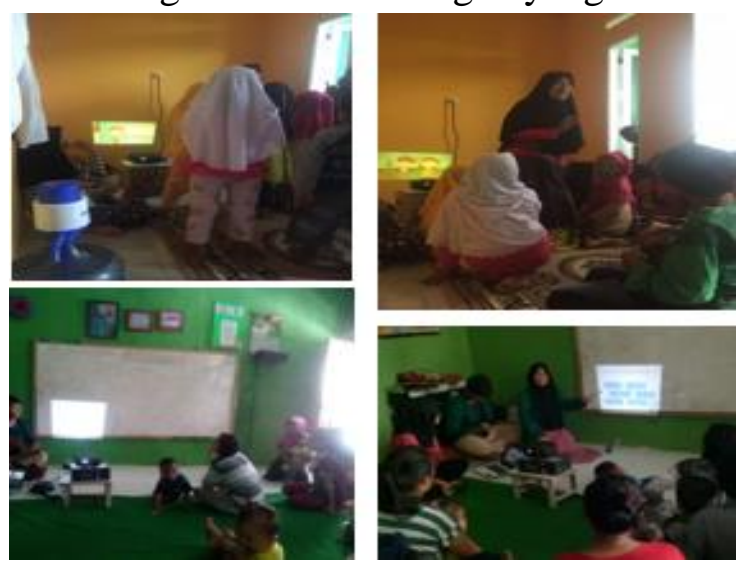

3. Pencegahan kekerasan seksual pada anak

Penyuluhan pencegahan kekerasan seksual pada anak ini dilakukan dua kali, yang pertama penyuluhan 
dilakukan kepada anak-anak kampung wates menggunakan media vidio dan lagu sentuhan boleh sentuhan tidak boleh. Materi yang diberikan mengenai pentingnya menjaga tubuh dari orang lain dan cara mencegah terjadinya pelecehan seksual pada anak. Penyuluhan yang kedua dilakukan kepada ibu-ibu yang memiliki anak dibawah 15 tahun. Materi yang diberikan adalah cara mendidik anak untuk terhindar dari kekerasan seksual.

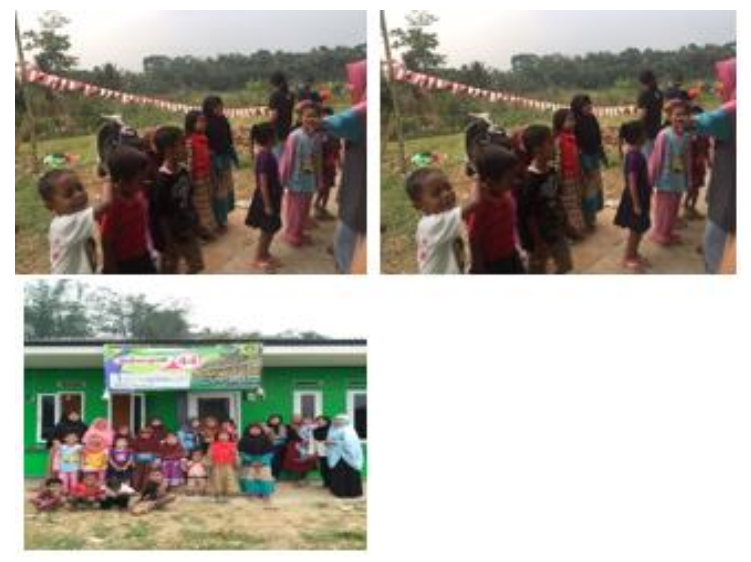

b) Senam sehat

Senam sehat ini dilaksanakan dua kali yaitu yang pertama adalah senam sehat di posko KKN 44 dengan peserta anakanak yang tinggal disekitar posko, dan yang kedua adalah senam pinguin dan SKJ yang dilaksanakan pada jam olahraga MI Nur Shidqul Wahid
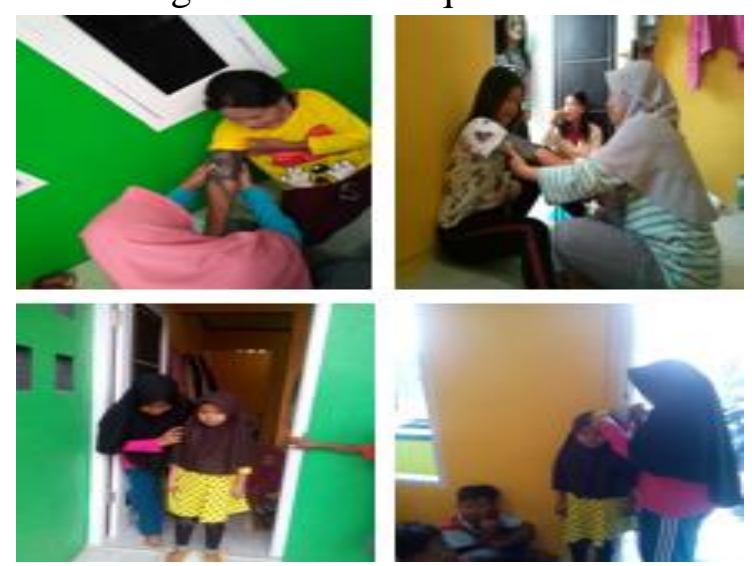

c) Cek kesehatan gratis

Kegiatan ini dilakukan untuk masyarakat kampung wates, cek kesehatan ini diantaranya adalah cek tekanan darah dan Indeks Masa Tubuh yang dilakukan di posko KKN 44.

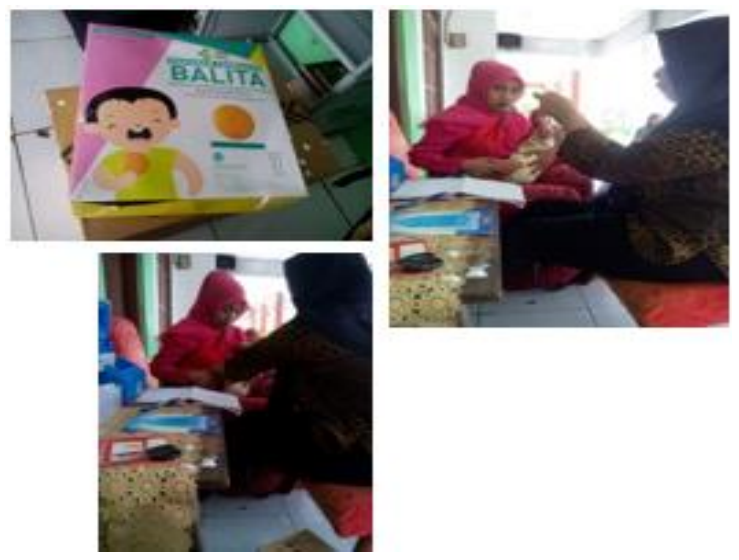

d) Membantu Kegiatan Posyandu

Dalam kegiatan posyandu kami hanya membantu dalam administrasi, menimbang bayi dan balita, serta membagikan makanan tambahan untuk bayi.

\section{Bidang Teknik}

a) Pelatihan Dasar Komputer

Materi yang diberikan mengenai pengenalan hardware laptop, cara penggunaan laptop dan fungsi laptop.

\section{KESIMPULAN DAN DAMPAK BAGI MASYARAKAT}

KKN Tematik Terintegrasi merupakan salah satu kegiatan yang memberikan peluang kepada para mahasiswa agar mempunyai pengalaman dalam Praktek lapangan diantaranya mengelola dana, wawasan dalam mengabdi di masyarakat, sehingga banyak hal-hal baru yang diperoleh. Tak hanya itu mahasiswa juga dapat merealisasikan rasa ingin tahunya, mereka melalui prosedur yang sistematis, yaitu dengan melakukan observasi, identifikasi masalah, cara menanggulangi masalah, merumuskan 
program, realisasi program, evaluasi dan penyusunan laporan program.

Kuliah kerja nyata $(\mathrm{KKN})$ yang telah dilaksanakan di Desa Gunung Bunder 1, Kecamatan Pamijahan, Kabupaten Bogor Rw. 01 Rt 03 selama 28 hari sejak 07 Agustus 2018 sampai 03 september 2017, Alhamdulillah mendapat sambutan yang antusias dari warga sekitar.

Dengan program-program yang kami rencanakan dibuat semenarik mungkin dan sesuai dengan kondisi lingkungan dan kebutuhan yang ada sehingga dapat berjalan dan mendapat dukungan baik dari masyarakat. Berkat kerjasama yang solid antar anggota kelompok, Dosen pembimbing lapangan kami dan bantuan dari masyarakat, hambatan dan kendala yang terjadi, dapat kami atasi dengan baik. Ini dikarenakan kegiatan KKN adalah kegiatan kelompok, bukan kegiatan Individual. Berikut kami sampaikan kegiatan-kegiatan yang kami telah jalankan

\section{Adapun dampak bagi masyrakat ialah :}

1. Meningkatnya pengetahuan masyarakat tentang informasi yang telah kami beri baik informasi tentang kesehatan, menabung, bahasa Inggris dan Bahasa Arab.

2. Tersedianya tongsampah di Sekolah, sehingga murid tidak ada alasan lagi untuk membuang sampah sembarangan.

3. Tersedianya petunjuk jalan seperti gapura, agar tamu yang datang ke Kampung Wates tidak lagi tersesat.

4. Mempermudah pembelajaran dengan menggunaan media, seperti video, menggunakan aplikasi video scribe, mediator, dll, agar anak-anak tidak bosan dengan pembelajaran biasanya.

5. Memberikan penyuluhan tentang menabung, agar masyarakat terutama anak-anak, rajin menabung untuk masa depan.

\section{SARAN}

Adapun saran untuk Desa Gunung Bunder 1 ialah :

1. Lebih terstruktur lagi dalam program desa terkhusus dalam bidang kesehatan, ekonomi serta pendidikan.

2. Alangkah baiknya untuk tersedianya sarana dan prasarana kesehatan yang lebih menunjang seperti Puskesmas.

3. Kondisi kepala desa yang sibuk membuat kami sulit untuk berkoordinasi.

4. Sebaiknya petugas desa melakukan program baik program pembangunan dan sebagainya dilakukan dengan merata di semua RW.

Adapun saran untuk RW dan masyarakat kampung wates

1. Lebih baik untuk lebih pendekatan kepada masyarakat disemua RT karena selama kami melakukan KKN di kampung wates masih adanya kesenjangan sosial antar masyarakat.

2. Kegiatan sekolah yang tidak teratur sebaiknya guru fokus mengajar kepada murid-murid dengan konsisten dan sungguh-sungguh.

3. Sebaiknya diadakan MCK untuk warga dapat mandi, mencuci dan konsumsi air dalam satu aliran dan lebih tertutup. 


\section{REFERENSI}

Haryoko, Sapto. 2009. Efektivitas Pemanfaatan Media Audio-Visual sebagai Alternatif

http://pkm.uika-

bogor.aceh.id/index.php/pkmp/issue/view/1. Diakses pada tanggal $\underline{07}$

Kholis, Ade. 2016. Belajar Melalui Bermain untuk Pengembangan Kreativitas dan

Kognitif Anak Usia Dini. Garut: Universitas Garut.

Notoatmodjo, Soekidjo (Dr.Prof).2005. Promosi Kesehatan Teori dan Aplikasi. Jakarta : PT. Asdi Mahasatya.

Notoatmodjo, Soekidjo (Dr.Prof).2011. Kesehatan Masyarakat Ilmu \& Seni Edisi Refisi

2011. Jakarta : PT. Asdi Mahasatya.

Notoatmodjo, Soekidjo (Dr.Prof).2014. Ilmu Perilaku Kesehatan. Jakarta : PT. Asdi Mahasatya.

Optimalisasi Model Pembelajaran. Makasar: Universitas Negeri Makasar.

Profil Desa Gunung Bunder 1.
September 2018, pukul 13:09 WIB.

Siregar, Suriani. 2015. Pengaruh Model Pembelajaran Talking Stick Terhadap Hasil Belajar dan Aktivitas Visual Siswa pada Konsep Sistem Indra. Aceh Tenggara: Universitas Gunung Leuser. 